\title{
Willmar Schwabe Award 2006: Antiplasmodial and Antitumor Activity of Artemisinin - From Bench to Bedside
}

Thomas Efferth

\begin{abstract}
Secondary metabolites from plants serve as defense against herbivores, microbes, viruses, or competing plants. Many medicinal plants have pharmacological activities and may, thus, be a source for novel treatment strategies. During the past 10 years, we have systematically analyzed medicinal plants used in traditional Chinese medicine and focused our interest on Artemisia annua L. (qinhao, sweet wormwood). We found that the active principle of Artemisia annua L., artemisinin, exerts not only antimalarial activity but also profound cytotoxicity against tumor cells. The inhibitory activity of artemisinin and its derivatives towards cancer cells is in the nano- to micromolar range. Candidate genes that may contribute to the sensitivity and resistance of tumor cells to artemisinins were identified by pharmacogenomic and molecular pharmacological approaches. Target validation was performed using cell lines transfected with candidate genes or corresponding knockout cells. The identified genes are from classes with diverse biological functions; for example, regulation of proliferation (BUB3, cyclins, $C D C 25 A$ ), angiogenesis (vascular en-
\end{abstract}

dothelial growth factor and its receptor, matrix metalloproteinase-9, angiostatin, thrombospondin-1) or apoptosis (BCL-2, BAX, $\mathrm{NF}-\kappa \mathrm{B})$. Artesunate triggers apoptosis both by p53-dependent and -independent pathways. Antioxidant stress genes (thioredoxin, catalase, $\gamma$-glutamylcysteine synthetase, glutathione $S$-transferases) as well as the epidermal growth factor receptor confer resistance to artesunate. Cell lines overexpressing genes that confer resistance to established antitumor drugs (MDR1, MRP1, BCRP, dihydrofolate reductase, ribonucleotide reductase) were not cross-resistant to artesunate, indicating that artesunate is not involved in multidrug resistance. The anticancer activity of artesunate has also been shown in human xenograft tumors in mice. First encouraging experience in the clinical treatment of patients suffering from uveal melanoma calls for comprehensive clinical trials with artesunate for cancer treatment in the near future.

\section{Key words}

Angiogenesis $\cdot$ apoptosis $\cdot$ artemisinin $\cdot$ artesunate $\cdot$ cluster analysis - comparative genomic hybridization $\cdot$ microarrays $\cdot$ oxidative stess $\cdot$ pharmacogenomics

\section{Introduction}

\section{Traditional Chinese medicine (TCM)}

Medicinal herbs from TCM hold a unique position since an enormous variety of drugs from plant origin is founded on more than 5000 years of tradition [1], [2]. Hence, it is assumed that many ineffective prescriptions have disappeared thereby significantly improving the prospect for identifying novel active constituents from TCM [3], [4]. Our interest in natural products from TCM was triggered in the $1990 \mathrm{~s}$ by sesquiterpene lactones of the artemisinin type from Artemisia annua L. [5]. The Artemisia genus is known to contain many bioactive compounds [6]. Apart from artemisinin, which is in the focus of the present review, we have analyzed cellular and molecular mechanisms of chemically characterized natural products derived from TCM. Among them were known compounds with still insufficiently defined modes of action, which were investigated by us with molecular biological and pharmacogenomic approaches, i.e., arsenic trioxide, ascari- 
dol, berberine, cantharidin, cephalotaxine, curcumin, homoharringtonine, luteolin, isoscopoletin, scopoletin and others [7], [8], [9], [10], [11], [12], [13], [14], [15]. Furthermore, several novel bioactive compounds were described and analyzed in the course of our investigations, i. e., tetracentronsine $\mathrm{A}$, tetracentronside $\mathrm{A}$, $\mathrm{B}$ and $\mathrm{C}$, the two novel $\alpha$-tetralone derivatives berchemiaside $\mathrm{A}$ and $\mathrm{B}$ as well as the novel flavonoid quercetin-3-O-(2-acetyl- $\alpha$ L-arabinofuranoside) [16], [17].

\section{Botany and geobotany of Artemisia annua L.}

This plant belongs to the family of Asteraceae and represents a strong aromatic shrub of $50-150 \mathrm{~cm}$ in height. The reproduction occurs by insect and self-pollination and wind distribution. The plant represents a typical neophyte in lowlands and hill countries in Asia and Europe with continental to subcontinental climate.

\section{History of artemisinin}

The first description of the Chinese herb Artemisia annua L. (sweet wormwood) dates back to the year $168 \mathrm{BC}$. The plant was mentioned in the prescriptions for 52 diseases in the Mawangdui tomb of the Han dynasty. The next historical tradition is from the year 1086 written by Shen Gua. In the "Handbook of Prescriptions for Emergency Treatment" Ge Hong (281 - 340 B.C.) recommended tea-brewed leaves to treat fever and chills. The "Compendium of Materia Medica" published by Li Shizen in 1596 cited Ge Hong's prescription. In the course of the Vietnam war, the Chinese government started an antimalarial research program to systematically search for antimalarial TCM plants to support the Vietnamese army. As a result, artemisinin (qinghaosu) was identified in 1972 as the active antimalarial constituent of Artemisia annua L. [18], [19]. Today, artemisinin is widely used worldwide to combat otherwise drug-resistant Plasmodium strains, cerebral malaria, and malaria in children [20]. While Artemisia annua and artemisinin were regarded by the World Health Organization (WHO) with much reluctance for a long time, the full potential was recently recognized.

Besides the use in the treatment of malaria, the bioactivity of artemisinin and its derivatives is much broader. As shown in recent years, its potential application includes the treatment of infections of Schistosoma, Pneumocystis carinii [21], Toxoplasma gondii [22], human cytomegaloviruses, Herpes simplex viruses, and hepatitis B and C [23], [24], [25], [26]. In the 1990 s, several groups recognized the cytotoxic activity of artemisinin and its derivatives against tumor cells [27], [28], [29], [30], [31]. The present review focuses on the antimalarial and anticancer activity of artemisinins.

\section{Antimalarial Activity}

Antimalarial drug resistance has spread and intensified during the past decades and represents a severe global challenge. It is estimated that 300-500 million human beings are infected each year and that $1.5-2.5$ million individuals die of malaria annually [32], [33]. The development of novel drugs did not parallel this dramatic occurrence of malaria, which even aggravated the problem. Artemisinin and its derivatives are, therefore, promising new drugs on the horizon, which are expected to ease the malaria burden worldwide.
Drug combinations based on artemisinins offer an effective possibility to counteract drug resistance [34]. Combination regimes prolong the useful therapeutic life of existing antimalarial drugs. The probability that a mutant strain of Plasmodium simultaneously exerts resistance to two drugs with different modes of action and different therapeutic targets is low. Combinations of drugs are generally accepted to improve treatment efficacy and to delay the selection of drug-resistant parasites [35]. Indeed, it has been shown that the cure rate of artesunate or artemether in combination with mefloquine increased up to $95-100 \%$ compared to monotherapy with artemisinin derivatives. Other combinations, i.e., artemisinin derivatives and lumefantrine, also improved cure rates [35]. Despite the recommendation of the WHO to use artemisinin-based combination therapies, in order to avoid the emergence of artemisinin resistance, the overall use of such a combination dosage was still unsatisfactory [36]. For this reason, WHO banned artemisinin monotherapy in the year 2006.

Artemisinins proved to be valuable in drug combinations since they are able to reduce the number of parasites by approximately $10^{4}$ per asexual cycle [37], [38]. Artemisinins are active within 48-72 h [39], [40]. This considerably reduces the number of parasites to be killed by a partner drug in a combination regimen. Since they inhibit the production of gametocytes, artemisinins are able to reduce transmission [41].

Another favorable feature of artemisinins is that they are active in the treatment of mild and severe forms of malaria. Severe malaria does not stop with clearing parasitemia. Even if parasites are cleared, the clinical symptoms associated with cerebral malaria may get worse. Besides the brain, other organs such as kidneys or lung can also be injured in severe malaria. Artemisinin has been proven as an effective anti-malarial drug for the treatment of cerebral malaria [42]. Artemisinin derivatives are generally well tolerated [43], [44]. Mild and reversible hematological and electrocardiographic abnormalities, such as neutropenia and first-degree heart block, were observed infrequently. Neurotoxicity, e.g., ataxia, slurred speech and hearing loss, have been reported in a few patients [45]. Due to their lack of severe side effects, artemisinins are also well suited for the treatment of malaria in children [46].

\section{Antitumor Activity of Artemisinin}

\section{Multifactorial nature of sensitivity and resistance to anticancer agents}

Rather than on the antimalarial activity of artemisinin and its derivatives, our own efforts were focused on the activity of these compounds towards cancer cells. During the past 10 years, we have analyzed molecular mechanisms of artemisinins. We were aware that analysis of the mode of action of a novel compound with activity against tumor cells is compromised by the fact that the response of tumor cells to cytotoxic agents is frequently determined by multiple factors and single mechanisms are not sufficient to account for a drug's activity [47], [48], [49], [50], [51], [52]. Although anticancer drugs are extremely divergent in their chemical and physical structures and biological actions, a synopsis of the relevant mechanisms influencing drug effects allows their categorization into (i) those acting upstream of the ac- 
tual drug target, (ii) those acting at critical target sites or (iii) those acting downstream of them [53], [54].

Mechanisms acting upstream include transporter proteins for uptake or excretion (i.e., ATP-binding cassette transporters, reduced folate carriers, and nucleoside transporters) and drug-metabolizing enzymes that activate, inactivate, or detoxify drugs (i.e., phase I/II enzymes). Metabolizing enzymes and transporter molecules often do not exhibit specificity for certain anticancer drugs but are operative towards a wide array of different xenobiotic drugs including anticancer agents. Drug-metabolizing enzymes may influence pharmacokinetics and -dynamics.

Drug target sites for alkylating agents and platinum drugs are DNA (and DNA repair mechanisms), RNA (RNA synthesis inhibitors, i.e., actinomycin D) and specific proteins such as DNA topoisomerases I/II (camptothecins, anthracyclines, and epipodophyllotoxins), tubulins (Vinca alkaloids and taxanes) or enzymes of DNA biosynthesis (antimetabolites).

Mechanisms downstream of the actual drug targets and at distinct intracellular locations are operative after injury by drugs has been taken place. The most important downstream mechanisms are the diverse apoptosis pathways. Their deregulation may lead to drug resistance and survival of cancer cells despite target molecules have been successfully targeted by anticancer drugs [55], [56]. Programmed cell death is not only regulated by the proteins directly involved in the apoptotic cascade but also by external factors, i.e., by chemokines that act as "survival factors" involved in prevention of apoptosis and, hence, contributing to survival and drug resistance of tumor cells after chemotherapeutic insult [57], [58].

It is, therefore, reasonable to propose that the same is true for cytotoxic compounds from traditional Chinese medicine such as artemisinin and its derivatives (Fig. 1). Since we did not know the relevant upstream, target site, and downstream mechanisms of this class of drugs at the beginning of our studies, we applied pharmacogenomic approaches [59], [60], [61], [62].

\section{Upstream mechanisms - multidrug resistance}

Importantly, artemisinin and its derivatives are used to treat otherwise drug-resistant Plasmodia strains due to their lack of lack of cross-resistance to these class of drugs [63]. Therefore, we addressed the question whether artemisinins are involved in the multidrug-resistance phenotype in tumor cells. Correlating the microarray-based mRNA expression of the multidrug resistance-conferring $A B C B 1$ gene (MDR1; P-glycoprotein) with the $\mathrm{IC}_{50}$ values for artemisinin and seven derivatives did not show significant relationships. Similarly, the flow cytometric measurement of the fluorescent probe rhodamine 123, which represents a functional assay for P-glycoprotein, did not reveal significant correlations to artemisinins [62]. To validate these results obtained by correlation analyses, we used cell lines overexpressing MDR1/P-glycoprotein and other drug resistance-conferring genes. We observed that artesunate was similarly active towards drug-sensitive and multidrug-resistant cell lines [60], [64], [65], which overexpress MDR1/P-glycoprotein (CEM/ADR5000; CEM/ VCR1000, CEM/VBL 100 ), MRP1 (CEM/E1000, HL60/AR) or BCRP (MDA-MB-231-BCRP). Likewise, methotrexate-resistant CEM/

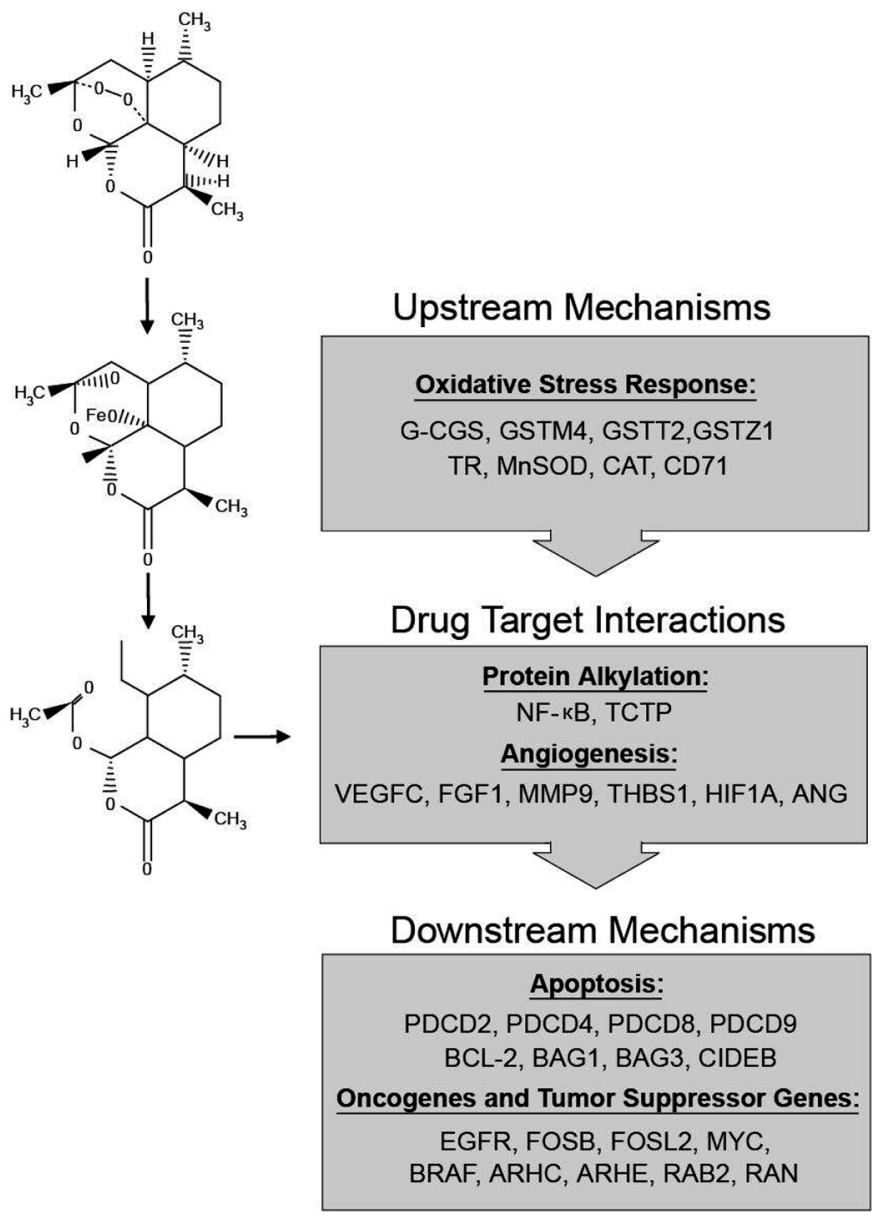

Fig. 1 Synopsis of mechanisms and candidate genes affecting the response of tumor cells to artesunate.

MTX1500LV cells with an amplification of the dihydrofolate reductase (DHFR) gene and hydroxyurea-resistant CEM/HUR90 cells with overexpression of ribonucleotide reductase (RRPM2) were not cross-resistant to artesunate. Artesunate modulated the uptake of doxorubicin in MRP1-overexpressing CEM/E1000 cells, but not in P-glycoprotein-overexpressing CEM/VCR1000 cells [65].

\section{Upstream mechanisms - oxidative stress response}

In Plasmodia, the cleavage of the endoperoxide moiety of artemisinin is facilitated by heme-iron. Hemoglobin of erythrocytes serves as an amino acid source for Plasmodium trophozoites and schizonts. The parasites take up hemoglobin and degrade it in their food vacuoles [66], [67]. The release of heme-iron during hemoglobin digestion facilitates the cleavage of the endoperoxide moiety of artemisinin by an Fe(II) Fenton reaction. Thereby, reactive oxygen species are generated, such as hydroxyl radicals and superoxide anions. They damage membranes of food vacuoles and lead to autodigestion [68], [69]. Furthermore, carbon-centered radical species are generated by the heme iron(II)mediated decomposition of artemisinin [70], [71], [72]. These highly reactive molecules are able to alkylate heme and several Plasmodium-specific proteins [73], [74], [75], [76]. It has also been discussed, however, that heme iron(II) and oxidative stress are not the only determinants of artemisinin's antimalarial activity [77]. 
Focusing on the anticancer activity of artemisinin and its derivatives, we compared the baseline antioxidant mRNA gene expression in the $\mathrm{NCI}$ cell line panel with the $\mathrm{IC}_{50}$ values for artesunate [78], [79], [80]. Our results are in favor of oxidative stress as a mechanism of action of artesunate against cancer cells. We found that thioredoxin reductase and catalase expression correlated significantly with the $\mathrm{IC}_{50}$ values for artesunate. WEHI7.2 mouse thymoma cells selected for resistance to hydrogen peroxide or transfected with thioredoxin, manganese superoxide dismutase or catalase showed resistance to artesunate as compared to the parental cell line. The microarray-based mRNA expression of dihydrodiol dehydrogenase, $\gamma$-glutamylcysteine synthase $(\gamma$-GCS; GLCLR), glutathione S-transferases GSTM4, GSTT2, GSTZ1 and microsomal glutathione S-transferase MGST3 correlated significantly with resistance to artesunate in the $\mathrm{NCl}$ cell line panel. A tendency for correlation $(0.05<\mathrm{p}<0.1)$ was observed for GSTA1, GSTA2, GSTP1 and MGST1. MSC-HL13 cells transfected with cDNAs for heavy and light subunits of $\gamma$-GCS were more resistant to artesunate than mock transfected MSVPC4 cells [60]. L-Buthionine sulfoximine, a $\gamma$-GCS inhibitor that depletes cellular glutathione pools completely, reversed artesunate resistance in MSV-HL13 cells [80].

As tumor cells contain much less iron than erythrocytes, but more than other normal tissues [81], the question arises as to whether iron may be critical for artemisinin's action towards tumor cells. Cellular iron uptake and internalization are mediated by binding of the transferrin-iron complexes to the transferrin receptor (CD71) expressed on the cell surface membrane and by subsequent endocytosis. While most normal tissues are CD71negative, CD71 is highly expressed in clinical tumors and is widely distributed among clinical tumors [82], [83]. We found that CD71 expression was much higher in CCRF-CEM and U373 tumor cells $(48-95 \%)$ than in peripheral mononuclear blood cells of healthy donors (<2\%) [84]. Iron(II) glycine sulfate (Ferrosanol ${ }^{\circledR}$ ) and transferrin increased the cytotoxicity of free artesunate, artesunate microencapsulated in maltosyl- $\beta$-cyclodextrin and artemisinin towards CCRF-CEM leukemia and U373 astrocytoma cells if compared with artemisinins applied without iron [84]. This effect was reversed by the monoclonal antibody RVS10 against the transferrin receptor, which competes with transferrin for binding to the receptor. The $\mathrm{IC}_{50}$ values for eight different artemisinin derivatives in the $\mathrm{NCI}$ cell lines were correlated with the microarray mRNA expression of 12 genes involved in iron uptake and metabolism. The mRNA expression of mitochondrial aconitase and ceruloplasmin (ferroxidase) correlated significantly with the $\mathrm{IC}_{50}$ values for artemisinins. Interestingly, exposure of artemisinin and its derivatives produces no or only marginal cytotoxicity to non-tumor cells. These results are in accordance with data from other authors [85], [86], [87]. We found that the growth of primary human fibroblasts is almost unaffected by artesunate concentrations up to $100 \mu \mathrm{M}$ [23]. This implies that tumors that express more CD71 than normal cells might be more affected by combination treatments of transferrin or Ferrosanol ${ }^{\circledR}$ plus artemisinin derivatives. The finding that iron(II) glycine sulfate increased the action of artemisinins is interesting since Ferrosanol ${ }^{\circledR}$ has been in clinical use for many years. Hence, artemisinins might be safely applied in combination with Ferrosanol ${ }^{\circledR}$ in a clinical setting.

\section{Target site interactions - protein alkylation}

As stated above, artemisinins alkylate specific proteins in the Plasmodium parasites, i.e., heme, translationally controlled tumor protein (TCTP) and sarco/endoplasmic reticulum $\mathrm{Ca}^{2+} \mathrm{ATPa}-$ ses (SERCA) [73], [74], [75], [76], [88]. Whereas SERCA of Plasmodia may be affected by artemisinin, it does probably not alkylate human SERCA [76]. We have addressed the question whether TCTP may also be important for artesunate's action in tumor cells. Interestingly, the microarray-based mRNA expression of TCTP correlated inversely with the $\mathrm{IC}_{50}$ values for artesunate in the $\mathrm{NCI}$ tumor cell line panel. Tumor cell lines with high TCTP expression were sensitive to artesunate while low TCTP expression was associated with resistance to artesunate. Although a functional role of TCTP for the activity of artemisinins against tumor cells has not been shown, these results suggest such a role. TCTP represents a proliferation-related $\mathrm{Ca}^{2+}$-binding protein, which associates transiently with microtubules during the cell cycle [89]. It has also been implicated in malignant transformation and apoptosis [90], [91].

Despite these results, it should also be considered that artemisinin and its derivatives might alkylate many protein species. It is, therefore, possible that a more unspecific broad-spectrum alkylation of proteins in tumor cells rather than the specific alkylation of target proteins account for the growth-inhibitory effects of artemisinins.

Furthermore, the question arises whether artemisinins may alkylate other nucleophilic molecules in the cell such as DNA. It has been reported that artemisinin does not alkylate the DNA of malaria parasites [88]. In own experiments, we did not find that artesunate damages DNA of tumor cells at concentrations able to inhibit tumor cell growth (unpublished data).

\section{Target site interactions - angiogenesis}

The outgrowth of new blood vessels from pre-existing ones is crucial for tumors to gain access to sufficient amounts of oxygen and nutrients [92]. If tumors reach a size for which diffusion alone cannot supply enough oxygen and nutrients, a process termed angiogenesis is promoted by numerous pro-angiogenic or anti-angiogenic factors. As a consequence, inhibitors of angiogenesis were considered as interesting for cancer treatment [93], [94]. Artemisinin and its derivatives inhibit angiogenesis as shown by several groups including our own [95], [96], [97], [98], [99].

We showed that the microarray-based mRNA expression of 30 out of 90 angiogenesis-related genes correlated significantly with the cellular response to artemisinins [100]. Among this panel were many fundamental angiogenic regulators such as vascular endothelial growth factor C (VEGFC), fibroblast growth factor-2 (FGF1), matrix metalloproteinase 9 (MMP9), thrombospondin-1 (THBS1), hypoxia-inducing factor- $\alpha$ (HIF1A), angiogenin $(A N G)$ and others. By means of hierarchical cluster analysis and cluster image mapping, we identified an expression profile that significantly determined the cellular resistance to several artemisinin derivatives, including artesunate, arteether, artemether and dihydroartemisinyl ester stereoisomer 1. Using Matrigel plugs injected subcutaneously into syngenic mice, we found that artesunate indeed strongly reduced angiogenesis in vivo 
[98]. Inhibition of tumor angiogenesis represents, therefore, an important determinant of the anti-tumor effects of artemisinin and its derivatives.

\section{Downstream mechanisms - apoptosis}

In cluster analyses of microarray experiments, we found that the programmed cell death genes 2, 4, 8, and 9 (PDCD2, PDCD4, $P D C D 8, P D C D 9$ ), BCL2-associated athanogenes 1 and 3 (BAG1, $B A G 3)$, death-associated protein 6 (DAXX), MAP-kinase activating death domain (MADD), cell death-inducing DFFA-like effector $\beta$ (CIDEB) and others are possible determinants of the tumor response to artesunate [60]. Since apoptosis is a common mechanism of cell death for most anti-cancer drugs, this may also apply for artemisinin and its derivatives. Indeed, artesunate induces apoptosis as first shown by us and subsequently by others [5], [101], [102], [103], [104], [105]. We identified several apoptosisregulating genes whose mRNA expression correlated significantly with the $\mathrm{IC}_{50}$ values for artesunate in the $\mathrm{NCI}$ cell lines [62]. WEHI7.2 cells transfected with the anti-apoptotic BCL2-gene were more resistant to artesunate than mock vector-transfected control cells [79], indicating that artesunate may induce apoptosis via the intrinsic mitochondrial pathway of cell death. Furthermore, we found that artesunate acts via p53-dependent and -independent pathways in isogenic p53+/+ p21WAF1/CIP1+/+, p53-/- p21WAF1/CIP1+/+ and p53+/+ p21WAF1/CIP1-/- colon carcinoma cells [60]. This was confirmed in a subsequent study with p53 wild-type TK6 and p53 mutated WTK1 lymphoblastic cells. In both cell lines, we observed a similar sensitivity towards artesunate [84].

\section{Downstream mechanisms - oncogenes and tumor suppressor genes}

Oncogenes and tumor suppressor genes frequently affect downstream processes in tumor cells, i.e., regulation of apoptosis, differentiation, proliferation etc. Therefore, we categorized the interrelationships between artemisinins and oncogenes/tumor suppressor genes as downstream mechanisms for systematic reasons in this review. The expression of several oncogenes and tumor suppressor genes correlated with the response to artesunate, including expression of epidermal growth factor receptor (EGFR), of the tumor growth factor $\beta$ (TGFB), of FBJ murine osteosarcoma viral oncogene homologue $\mathrm{B}$ (FOSB), of FOS-like antigen2 (FOSL2), of the multiple endocrine neoplasia 1 gene (MEN1), of $v$-myb avian myeloblastosis viral oncogene homologue (MYB), of $v$-myc avian myelocytomatosis viral oncogene homologue (MYC), of $c$-src tyrosine kinase (CSK), of $v$-raf murine sarcoma viral oncogene homologue $\mathrm{B} 1$ (BRAF), of the RAS oncogene family members $A R H C, A R H E, R A B 2$ and $R A N$, of the breast cancer susceptibility gene 2 (BRCA2) and of others [60].

EGFR represents an exquisite target for therapeutic interventions. It contributes to the development of drug resistance, and EGFR-coupled signal transduction pathways activate mitogenic and other cancer-promoting processes, e.g., proliferation, angiogenesis, and inhibition of apoptosis [106]. For this reason, we analyzed it in more detail. In agreement with the microarray data, we found that glioblastoma cells transfected with a deletionactivated EGFR cDNA were more resistant to artesunate than the control cells [60].
Furthermore, we found synergistic effects for the combination treatment with the EGFR tyrosine kinase inhibitor erlotinib (Tarceva, OSI-774) and artesunate in glioblastoma cells transfected with a deletion-activated EGFR cDNA and we found additive effects in wild-type EGFR transfectants [107]. We determined a profile of chromosomal gains and losses by comparative genomic hybridization in nine non-transfected glioblastoma cell lines. The correlation of the genomic aberrations in these cell lines with the $\mathrm{IC}_{50}$ values for the combination treatment of artesunate and erlotinib pointed to certain genomic loci. The identified genes may serve as candidate genes for determining sensitivity and resistance. Currently, they are under further investigation.

\section{Preclinical and preliminary clinical studies}

The activity of artemisinin and its derivatives in vivo has been shown by several authors. Moore et al. [85] found that the growth of fibrosarcoma in Fisher 344 rats was significantly delayed by the daily application of the active metabolite of artemisinin, dihydroartemisinin, plus ferrous sulfate if compared to untreated control animals. Chen et al. [108] used the chorioallantoic membrane (CAM) assay in chicken eggs. It is widely accepted for analysis of the development of blood vessels in vivo. The CAM assay is particularly suited for the screening of angiogenesis inhibitors. Dihydroartemisinin significantly suppressed neoangiogenesis in this test system. These results correlate with results of our own investigations [98]. We soaked Matrigel plugs with vascular epithelial growth factor (VEGF), tumor necrosis factor$\alpha(\mathrm{TNF}-\alpha)$ and heparin, which act as strong stimuli for angiogenesis. The Matrigel plugs were subcutaneously injected into nude mice. In control animals without artesunate treatment, a strong vascularization-based filling of the plugs with blood took place after four days. In contrast, a statistically significant reduction in Matrigel vascularization was observed in mice fed with artesunate in the drinking water. To determine the in vivo effects of artesunate on tumor growth, we subcutaneously injected KSIMM Kaposi sarcoma cells to nude mice [98]. Whereas strong tumor growth was found in untreated mice, it was strongly suppressed in artesunate-treated animals. These results were subsequently confirmed by other authors. Disbrow et al. [109] found that dihydroartemisinin inhibited virus-induced tumor formation in vivo. Dogs infected with canine oral papillomavirus developed tumors in the oral mucosa. The tumor development was, however, significantly inhibited by topical application of dihydroartemisinin. Lai and Singh [110] induced breast cancer in rats by application of 7,12-dimethylbenzo[a]anthracene (DMBA). In comparison to untreated control animals, rats fed with artemisinin showed delayed tumor development and decreased tumor size. Furthermore, fewer rats showed multiple breast tumors, and the occurrence of tumors was generally lowered.

The successful treatment of human xenograft tumors in nude mice with artesunate [98] encouraged us to apply artesunate in a clinical setting. We have treated two patients suffering from uveal melanoma on a compassionate-use basis after standard chemotherapy alone was ineffective in stopping tumor growth [111]. Generally, such tumor patients have a median survival time of 2-5 months. Upon use of artesunate, no additional side effects exceeding those caused by standard chemotherapy were observed indicating that artesunate was well tolerated. One pa- 
tient experienced a temporary response after the addition of artesunate while the disease was progressing under standard therapy with fotemustine alone. The patient died after 24 months. The second patient first experienced a stabilization of the disease following use of artesunate plus iron in combination with the standard drug dacarbazine followed by objective regressions of splenic and lung metastases. This patient is still alive 47 months after first diagnosis of stage IV uveal melanoma. This promising result indicates that artesunate might be a valuable adjuvant drug for the treatment of melanoma and other tumors in combination with standard chemotherapy. The treatment of a pituitary macroadenoma with artemether has been reported recently [112]. Comprehensive clinical trails are needed to establish the efficacy of artesunate in cancer therapy.

\section{Mechanistic Basis for Common Modes of Action of Artemisinin in Plasmodium and Cancer}

\section{Reactive oxygen species, radical molecules and iron}

After absorption, artemisinin derivatives such as artesunate are metabolized in the liver by phase II enzymes (cytochrome P450 monoxygenases) to dihydroxyartemisinin, which retains its bioactivity. Artemisinin itself is not converted to dihydroxyartemisinin [113], [114].

In malaria parasites, artemisinin acts by a two-step mechanism. It is first activated by intraparasitic heme-iron, which catalyzes the cleavage of the endoperoxide. The Plasmodium trophozoites and schizonts live within red blood cells. Here, they take up and digest hemoglobin. The heme-derived iron facilitates the cleavage of artemisinin's endoperoxide moiety by a Fe(II) Fenton reaction. This results in the generation of reactive oxygen species and carbon-centered radical species [68], [69], [70], [71], [72]. Cleavage of the endoperoxide bond of artemisinin and its derivatives leads to the alkylation of heme and some Plasmodiumspecific proteins, including the $P$. falciparum translationally controlled tumor protein (TCTP), histidine-rich protein (42 kDa) and PfATP6, the sarco-/endoplasmic reticulum $\mathrm{Ca}^{2+}$ ATPase (SERCA) orthologue of P. falciparum [73], [74], [75]. Binding of artemisinin to the parasite's DNA has not been observed [115].

As the iron storage in tumor cells is generally decreased compared to that of erythrocytes but increased in tumor cells if compared to normal cells [81], the question arises as to whether iron may also play a role in the inhibitory action of artemisinins towards tumor cells [116]. The growth rate of a tumor was significantly slowed down by daily oral administration of ferrous sulfate followed by dihydroartemisinin. No significant tumor growth retardation effect was observed in rats treated with either dihydroartemisinin or ferrous sulfate alone. Drug treatment did not significantly affect body weight if compared with untreated tumor-implanted animals, and no apparent toxic effect was observed after drug treatment [85]. Iron(II) glycine sulfate $\left(\right.$ Ferrosanol ${ }^{\circledR}$ ) and transferrin increased the cytotoxicity of free artesunate, artesunate microencapsulated in maltosyl- $\beta$-cyclodextrin and artemisinin towards CCRF-CEM leukemia and U373 astrocytoma cells if compared with that of artemisinin applied without iron [84]. Growth inhibition by artesunate and ferrous iron correlated with induction of apoptosis. The effect of ferrous iron and transferrin was reversed by the monoclonal antibody RVS10 against the transferrin receptor, which competes with transferrin for binding to the receptor. The $\mathrm{IC}_{50}$ values for eight different artemisinin derivatives in the $\mathrm{NCI}$ cell line panel were correlated with the microarray mRNAexpression of 12 genes involved in iron uptake and metabolism in order to identify ironresponsive cellular factors enhancing the activity of artemisinins. This analysis pointed to mitochondrial aconitase and ceruloplasmin (ferroxidase). Interestingly, exposure of artemisinin and its derivatives produces no or only marginal cytotoxicity to normal peripheral blood mononuclear cells (PBMC).

\section{Role of the transcription factor NF- $\mathrm{kB}$}

Artemisinin-type compounds belong to the class of sesquiterpenes. This is a group of natural products present in medicinal plants all over the world with well-known anti-inflammatory activities. Several investigations showed that the anti-inflammatory activity is at least in part due to inhibition of the nuclear transcription factor $\kappa \mathrm{B}$ (NF- $\kappa \mathrm{B})$ [117], [118], [119]. Molecular docking studies using the three-dimensional crystal structure of $\mathrm{NF}-\mathrm{\kappa B}$ revealed that many sesquiterpene lactones attack the cysteine-38 residue of the $\mathrm{p} 54 / \mathrm{NF}-\kappa \mathrm{B}$ subunit [120], [121], [122], [123].

In 2002, we were the first to demonstrate that artesunate inhibits NF- $\kappa B$ activity, leading to the inhibition of viral replication. $\mathrm{NF}-\mathrm{KB}$ is involved in the transcriptional regulation of immediate early, early and late proteins of human cytomegalovirus (HCMV) necessary for viral replication [23]. Subsequent studies also support a role of artemisinin-type compounds in NF- $\kappa$ B inhibition. Aldieri et al. [124] found that artemisinin inhibits NF- $\kappa B$ activity and thereby blocks nitric oxide synthesis. Dihydroarteannuin, a semisynthetic derivative of artemisinin, is also able to inhibit NF- $\kappa B$ [125]. Tripathi et al. [126] reported increased expression levels of the adhesion molecule ICAM-1 (intercellular cell adhesion molecule-1) in human brain microvascular endothelial cells (HBMEC) after exposure to artemisinin. ICAM-1 is involved in sequestration of Plasmodium falciparum-infected erythrocytes in the postcapillary brain endothelium. This represents a typical feature of cerebral malaria pathogenesis. Artemisinin reduced ICAM-1 expression in endothelial cells. As ICAM-1 expression is regulated by NF- $\kappa \mathrm{B}$, it is reasonable that artemisinin improves the therapeutic efficacy in cerebral complications during malaria infections. These results suggest that there is a common mechanistic basis for explaining the effects of artemisinin and its derivatives against malaria infections, viral infections and tumor cells.

\section{Biotechnological Approaches for the Production of Artemisinin}

The yield of artemisinin in wild populations of Artemisia annua is low $(0.01-0.8 \%)$. Therefore, there is a considerable limitation to commercialization of the drug [127], [128]. Total synthesis of the product is feasible but time-consuming and expensive. Several synthesis routes with (-)-isopulegol, (+)-isolimenene or (R)-(+)pulegone as starting molecules have been described [129], [130], [131] (Fig. 2). The semi-synthetic production of artemisinin from its precursor artemisinic acid has also been shown. Artemisinic 
A Schmid and Hofheinz (1983):

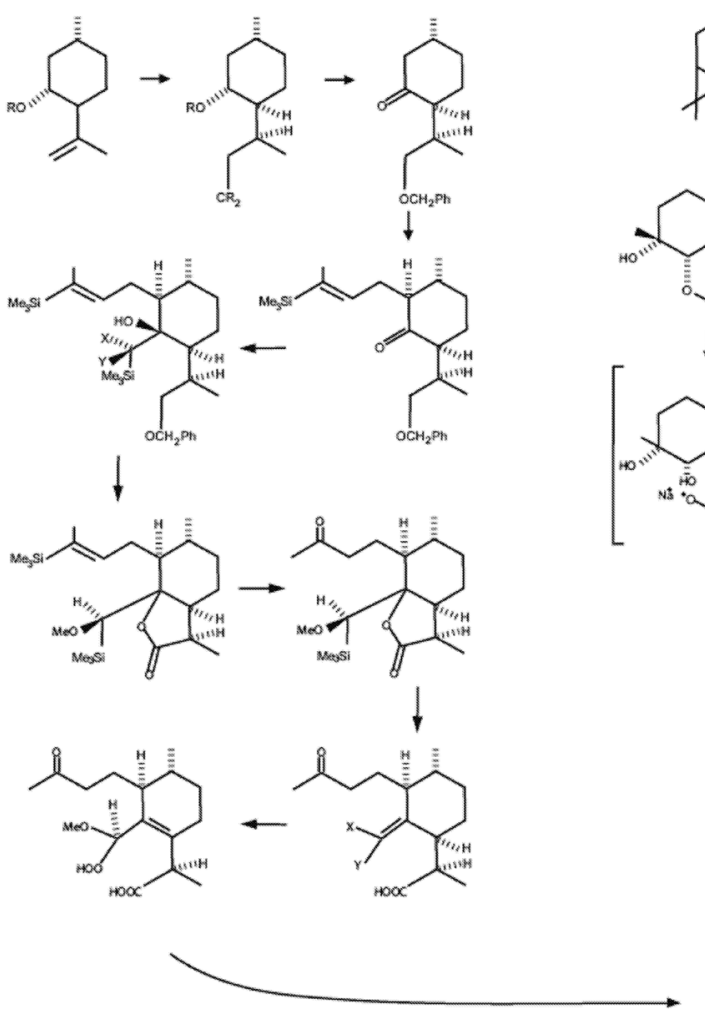

B Ravindrananthan et al. (1990):<smiles>CC1=CCC2CC1C2</smiles><smiles>C=C(C)C1C=CC(C)CC1</smiles><smiles>CCC(C)(C)[C@]1(C)C=CC(C)CC1</smiles><smiles>[3H]</smiles>

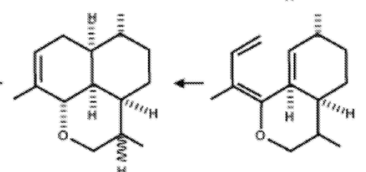
西

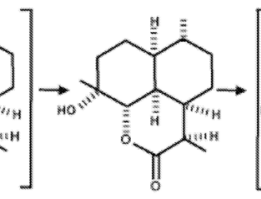

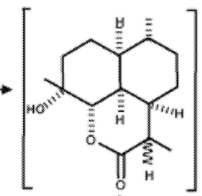

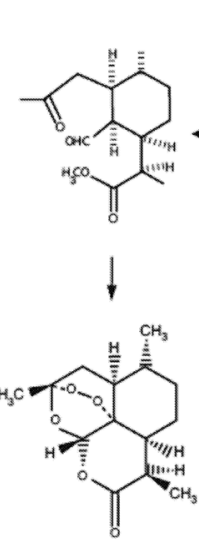

C Avery et al. (1992):

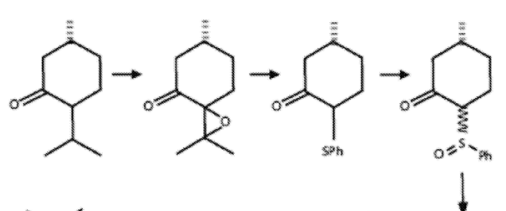

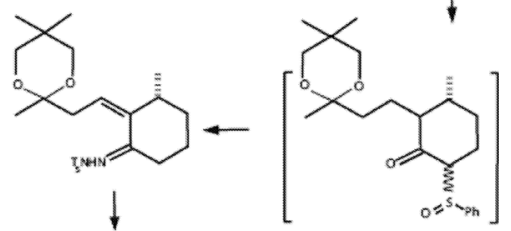<smiles>CCCCC1C(=O)CCCC1CC1CCC(C)(C)C(C)(C)C1</smiles><smiles>CC(C)C1CCC(C)C(CCC2(C)CCC(C)(C)C2)C1C(C)C</smiles>
has been elucidated, and the corresponding genes have been cloned. In brief, starting from the cytosolic MVA pathway (3R-mevalonic acid) and 3-acetyl-CoA on one side and from the plasticidal DXP pathway (1-deoxy-D-xylulose 5-phosphate), pyruvate and glyceraldehyde 3-phosphate as starting molecules on the other side, several enzymatic steps lead to the synthesis of farnesyl diphosphate. Several further enzymatic reactions result in the generation of dihydroartemisinic acid and artemisinin (Fig. 3) (for a detailed representation of the biosynthesis of artemisinin, see reviews [143], [144]. If coding genes of these enzymes are transferred to microorganisms such as bacteria or yeast, it should be possible to reconstruct the biosynthetic pathway of artemisinin in these organisms. 
Cytosolic MVA Pathway

306

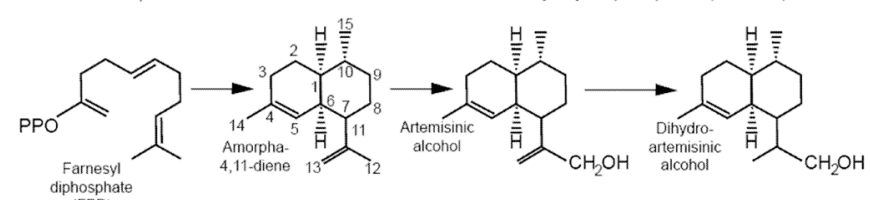

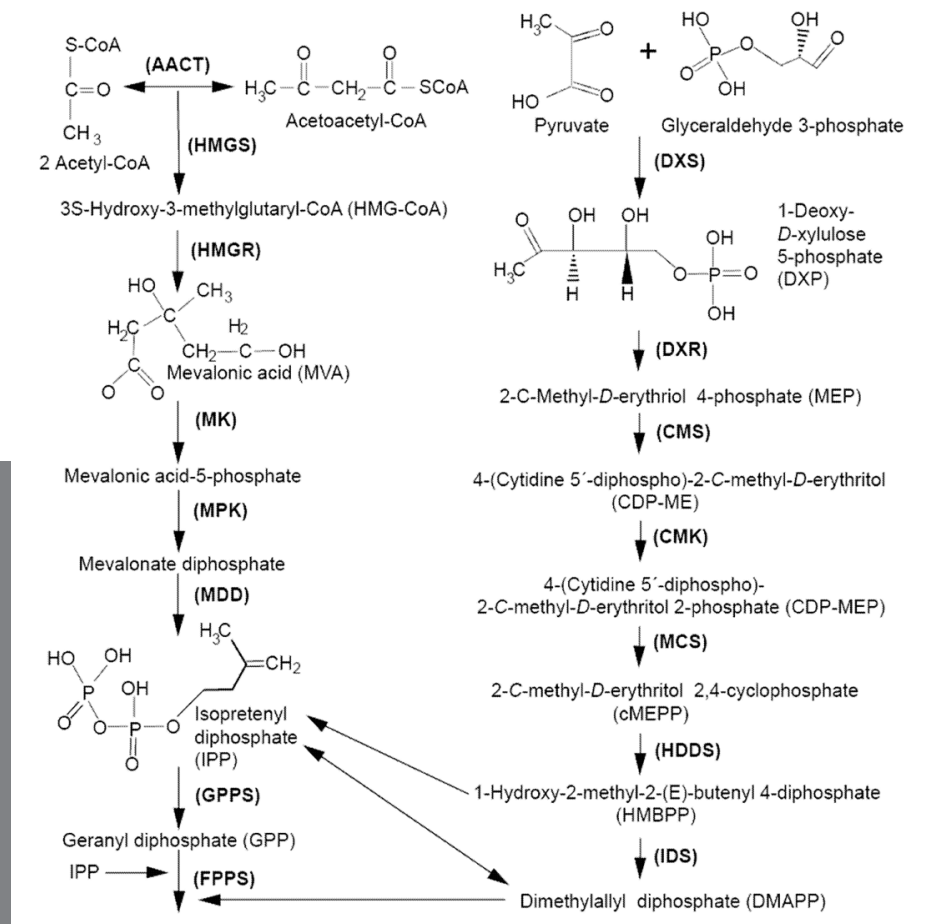

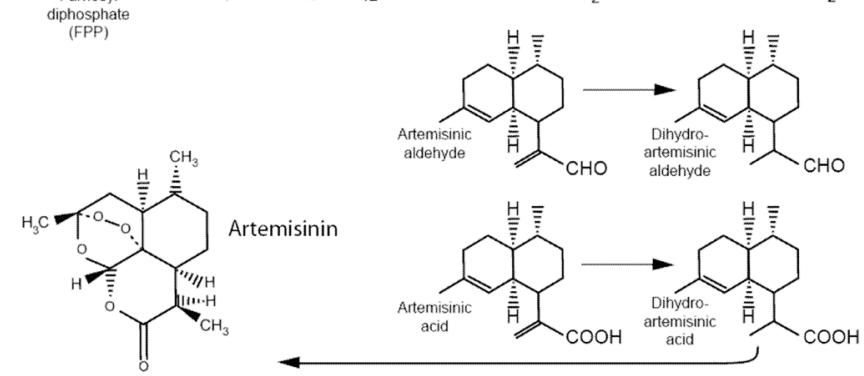

Fig. 3 Biosynthesis of artemisinin in Artemisia annua L.

Biotechnological approaches for the large-scale production of artemisinin represent a technical challenge. The obtainable yields should exceed the ones obtained by classical breeding methods. The artemisinin yield of one ton dry leaves of wild-type Artemisia annua is $6 \mathrm{~kg}$ per hectar. Time to grow is $100-120$ days allowing three harvests per year under optimal conditions $18 \mathrm{~kg}$ artemisinin/hectar and year. With the use of genetically engineered organisms, it should be possible to produce $25 \mathrm{~kg}$ artemisinin within an 8-hours working day. This calculation is based on the assumption that engineered yeast will produce $100-150 \mathrm{mg}$ artemisinin per liter culture medium or $100-150 \mathrm{~g} / 1000$ liter in an industrial set-up. The doubling time of yeast is about $1 \mathrm{~h}$; hence, starting with $100 \mathrm{~g}$ artemisinin at time point 0 will result in $25.6 \mathrm{~kg}$ artemisinin after $8 \mathrm{~h}$.

With the implementation of sophisticated biotechnological production techniques, it will be possible to meet the high demand for artemisinin for malaria treatment and hopefully in the future for cancer chemotherapy as well.

\section{References}

1 Tang W, Hemm I, Bertram B. Recent development of antitumor agents from Chinese herbal medicines; part I. Low molecular compounds. Planta Med 2003; 69: 97 - 108.

2 Tang W, Hemm I, Bertram B. Recent development of antitumor agents from Chinese herbal medicines. Part II. High molecular compounds (3). Planta Med 2003; 69: 193-201.

3 Natural compounds in cancer therapy. Portland: Oregon Medical Press; 2001.

4 Newman DJ, Cragg GM, Snader KM. atural products as sources of new drugs over the period 1981 - 2002. J Nat Prod 2003; 66: 1022 - 3 .

5 Efferth T, Rücker G, Falkenberg M, Manns D, Olbrich A, Fabry U et al. Detection of apoptosis in KG-1a leukemic cells treated with investigational drugs. Arzneimittelforschung 1996; 46: 196-200.

6 Tan RX, Zheng WF, Tang HQ. Biologically active substances from the genus Artemisia. Planta Med 1998; 64: 295-302.

7 Efferth T, Olbrich A, Sauerbrey A, Ross DD, Gebhart E, Neugebauer M. Activity of ascaridol from the anthelmintic herb Chenopodium anthelminticum L. against sensitive and multidrug-resistant tumor cells. Anticancer Res 2002; 22: 4221 - 4.

8 Efferth T, Sauerbrey A, Halatsch ME, Ross DD, Gebhart E. Molecular modes of action of cephalotaxine and homoharringtonine from the coniferous tree Cephalotaxus hainanensis in human tumor cell lines. Naunyn Schmiedebergs Arch Pharmacol 2003; 367: 56-67.

9 Efferth T, Kaina B. Microarray-based prediction of cytotoxicity of tumor cells to arsenic trioxide. Cancer Genomics Proteomics 2004; 1 : $363-70$.

10 Efferth T, Chen Z, Kaina B, Wang G. Molecular determinants of response of tumor cells to berberine. Cancer Genomics Proteomics 2005; 2: 115-24.

11 Efferth T, Rauh R, Kahl S, Tomicic M, Bochzelt H, Tome ME et al. Molecular modes of action of cantharidin in tumor cells. Biochem Pharmacol 2005; 69: $811-8$.

12 Efferth T. Microarray-based prediction of cytotoxicity of tumor cells to cantharidin. Oncol Rep 2005; 13: 459-63.

13 Rinner B, Siegl V, Purstner P, Efferth T, Brem B, Greger H et al. Activity of novel plant extracts against medullary thyroid carcinoma cells. Anticancer Res 2004; 24: 495 - 500.

14 Adams M, Efferth T, Bauer R. Activity-guided isolation of scopoletin and isoscopoletin, the inhibitory active principles towards CCRFCEM leukaemia cells and multi-drug resistant CEM/ADR5000 cells, from Artemisia argyi. Planta Med 2006; 72: 862-4.

15 Fu YJ, Efferth T, Zu YG. Optimization of luteolin separation from pigeonpea [Cajanus Cajan (L.) Millsp.] leaves by macroporous resins. J Chromatogr A 2006; 1137: 145-52.

16 Wang YF, Cao JX, Efferth T, Lai GF, Luo SD. Cytotoxic and new tetralone derivatives from Berchemia floribunda (Wall.) Brongn. Chem Biodivers 2006; 3: 646-53.

17 Wang YF, Lai GF, Efferth T, Cao JX, Luo SD. New glycosides from Tetracentron sinense and their cytotoxic activity. Chem Biodivers 2006; 3: $1023-30$.

18 Klayman DL. Qinghaosu (artemisinin): an antimalarial drug from China. Science 1985; 228: 1049-55.

19 Li Y, Wu YL. How Chinese scientists discovered qinghaosu (artemisinin) and developed its derivatives. What are the future perspectives? Med Trop 1998; 58: 9S-12S.

20 Yeung S, Pongtavornpinyo W, Hastings IM, Mills AJ, White NJ. Antimalarial drug resistance, artemisinin-based combination therapy, and the contribution of modeling to elucidating policy choices. Am J Trop Med Hyg 2004; 71: 179-86.

21 Merali S, Meshnick SR. Susceptibility of Pneumocystis carinii to artemisinin in vitro. Antimicrob Agents Chemother 1991; 35: 1225-7.

22 Ke OY, Krug EC, Marr JJ, Berens RL. Inhibition of growth of Toxoplasma gondii by qinghaosu and derivatives. Antimicrob Agents Chemother 1990; 34: $1961-5$.

23 Efferth T, Marschall M, Wang X, Huong SM, Hauber I, Olbrich A et al. Antiviral activity of artesunate towards wild-type, recombinant, and ganciclovir-resistant human cytomegaloviruses. J Mol Med 2002; 80: $233-42$.

24 Romero MR, Efferth T, Serrano MA, Castano B, Macias RI, Briz O et al. Effect of artemisinin/artesunate as inhibitors of hepatitis B virus production in an "in vitro" replicative system. Antiviral Res 2005; 68: $75-83$. 
25 Kaptein SJ, Efferth T, Leis M, Rechter S, Auerochs S, Kalmer M et al. The anti-malaria drug artesunate inhibits replication of cytomegalovirus in vitro and in vivo. Antiviral Res 2006; 69: 60-9.

26 Romero MR, Serrano MA, Vallejo M, Efferth T, Alvarez M, Marin JJ. Antiviral effect of artemisinin from Artemisia annua against a model member of the Flaviviridae family, the Bovine Viral Diarrhoea Virus (BVDV). Planta Med 2006; 72: 1169-74.

27 Sun WC, Han JX, Yang WY, Deng DA, Yue XF. Antitumor activities of 4 derivatives of artemisic acid and artemisinin $B$ in vitro. Acta Pharmacol Sin 1992; 13: 541 - 3

28 Woerdenbag HJ, Moskal TA, Pras N, Malingre TM, el-Feraly FS, Kampinga $\mathrm{HH}$ et al. Cytotoxicity of artemisinin-related endoperoxides to Ehrlich ascites tumor cells. J Nat Prod 1993; 56: 849-56.

29 Zheng GQ. Cytotoxic terpenoids and flavonoids from Artemisia annua. Planta Med 1994; 60: 54 - 7 .

30 Lai H, Singh NP. Selective cancer cell cytotoxicity from exposure to dihydroartemisinin and holotransferrin. Cancer Lett 1995; 91: 41 - 6.

31 Beekman AC, Barentsen AR, Woerdenbag HJ, Van Uden W, Pras N, Konings AW et al. Stereochemistry-dependent cytotoxicity of some artemisinin derivatives. J Nat Prod 1997; 60: 325-30.

32 Butler D. Time to put malaria control on the global agenda. Nature 1997; 386: $535-41$.

33 World Health Organization. Severe falciparum malaria. Trans R Soc Trop Med Hyg 2000; 94: 1 - 75.

34 White NJ. Antimalarial drug resistance. J Clin Invest 2004; 113: $1084-92$

35 Silachamroon U, Krudsood S, Phophak N, Looareesuwan S. Management of malaria in Thailand. Korean J Parasitol 2002; 40: 1 - 7.

36 Mutabingwa TK. Artemisinin-based combination therapies (ACTs): best hope for malaria treatment but inaccessible to the needy!. Acta Trop 2005; 95: 305-15.

37 White N. Antimalarial drug resistance and combination chemotherapy. Philos Trans R Soc London B Biol Sci 1999; 354: 739-49.

38 Yeung S, Pongtavornpinyo W, Hastings IM, Mills AJ, White NJ. Antimalarial drug resistance, artemisinin-based combination therapy, and the contribution of modeling to elucidating policy choices. Am J Trop Med Hyg 2004; 71: 179-86.

39 Mishra SK, Asthana OP, Mohanty S, Patnaik JK, Das BS, Srivastava JS et al. Effectiveness of $\alpha, \beta$-arteether in acute falciparum malaria. Trans $\mathrm{R}$ Soc Trop Med Hyg 1995; 89: 299-302.

40 Mohanty S, Mishra SK, Satpathy SK, Satpathy S, Patnaik JK. Alphabeta arteether for the treatment of complicated falciparum malaria. Trans R Soc Trop Med Hyg 1997; 91: 328 - 30.

41 Price RN, Nosten F, Luxemburger C, ter Kuile FO, Paiphun L, Chongsuphajasiddhi $\mathrm{T}$ et al. Effects of artemisinin derivatives on malaria transmissibility. Lancet 1996; 347: 1654-8.

42 Mohanty S, Patel DK, Pati SS, Mishra SK. Adjuvant therapy in cerebral malaria. Indian J Med Res 2006; 124: 245-60.

43 Ribeiro IR, Olliaro P. Safety of artemisinin and its derivatives. A review of published and unpublished clinical trials. Med Trop (Mars) 1998; 58: 50-3.

44 Adjuik M, Babiker A, Garner P, Olliaro P, Taylor W, White N. International Artemisinin Study Group. Artesunate combinations for treatment of malaria: meta-analysis. Lancet 2004; 363: 9-17.

45 Davies TME, Karunajeewa HA, Ilett KF. Artemisinin-based combination therapies for uncomplicated malaria. Med J Aust 2005; 182: $181-5$.

46 Bar-Zeev N, White N. Evidence behind the WHO guidelines: Hospital Care for Children: efficacy and safety of artemisinin derivatives in children with malaria. J Trop Pediatr 2006; 52: 78 -82.

47 Efferth T, Mattern J, Volm M. Immunohistochemical detection of Pglycoprotein, glutathione $S$-transferase and DNA topoisomerase II in human tumors. Oncology 1992; 49: 368 - 75.

48 Efferth T, Volm M. Reversal of doxorubicin-resistance in sarcoma 180 tumor cells by inhibition of different resistance mechanisms. Cancer Lett 1993; 70: 197-202.

49 Volm M, Kästel M, Mattern J, Efferth T. Expression of resistance factors (P-glycoprotein, glutathione S-transferase-pi, and topoisomerase II) and their interrelationship to proto-oncogene products in renal cell carcinomas. Cancer 1993; 71: 3981 - 7.

50 Volm M, Koomägi R, Mattern J, Efferth T. Expression profile of genes in non-small cell lung carcinomas from long-term surviving patients. Clin Cancer Res 2002; 8: 1843 -8.
51 Volm M, Koomägi R, Mattern J, Efferth T. Protein expression profiles indicative for drug resistance of non-small cell lung cancer. Br J Cancer 2002; 87: $251-7$.

52 Volm M, Koomägi R, Efferth T. Prediction of drug sensitivity and resistance of cancer by protein expression profiling. Cancer Genomics Proteomics 2004; 1: 157-66.

53 Efferth T, Grassmann R. Impact of viral oncogenesis on responses to anti-cancer drugs and irradiation. Crit Rev Oncog 2000; 11: 165-87.

54 Efferth T, Volm M. Pharmacogenetics for individualized cancer chemotherapy. Pharmacol Ther 2005; 107: 155- 76.

55 Efferth T, Fabry U, Osieka R. Apoptosis and resistance to daunorubicin in human leukemic cells. Leukemia 1997; 11: 1180-6.

56 Pommier Y, Sordet O, Antony S, Hayward RL, Kohn KW. Apoptosis defects and chemotherapy resistance: molecular interaction maps and networks. Oncogene 2004; 23: 2934 -9.

57 Lotem J, Sachs L. Control of apoptosis in hematopoiesis and leukemia by cytokines, tumor suppressor and oncogenes. Leukemia 1996; 10 : $925-31$.

58 Efferth T, Fabry U, Osieka R. Interleukin-6 affects melphalan-induced DNA damage and repair in human multiple myloma cells. Anticancer Res 2002; 22: 231 - 4 .

59 Efferth T, Olbrich A, Bauer R. mRNA expression profiles for the response of human tumor cell lines to the antimalarial drugs artesunate, arteether, and artemether. Biochem Pharmacol 2002; 64: 617-23.

60 Efferth T, Sauerbrey A, Olbrich A, Gebhart E, Rauch P, Weber HO et al. Molecular modes of action of artesunate in tumor cell lines. Mol Pharmacol 2003; 64: 382-94.

61 Efferth T. Mechanistic perspectives for 1,2,4-trioxanes in anti-cancer therapy. Drug Resist Updat 2005; 8: 85 - 97.

62 Efferth T. Molecular pharmacology and pharmacogenomics of artemisinin and its derivatives in cancer cells. Curr Drug Targets 2006; 7: 407-21.

63 Price R, van Vugt M, Nosten F, Luxemburger C, Brockman A, Phaipun L et al. Artesunate versus artemeter for the treatment of recrudescent multidrug-resistant falciparum malaria. Am J Trop Med Hyg 1998; 59: $883-8$.

64 Efferth T, Dunstan H, Sauerbrey A, Miyachi H, Chitambar CR. The antimalarial artesunate is also active against cancer. Int J Oncol 2001; 18: 767-73.

65 Efferth T, Davey M, Olbrich A, Rücker G, Gebhart E, Davey R. Activity of drugs from traditional Chinese medicine toward sensitive and MDR1- or MRP1-overexpressing multidrug-resistant human CCRFCEM leukemia cells. Blood Cells Mol Dis 2002; 28: 160-8.

66 Semenov A, Olson JE, Rosenthal PJ. Antimalarial synergy of cysteine and aspartic protease inhibitors. Antimicrob Agents Chemother 1998; 42: 2254-8

67 Shenai BR, Sijwali PS, Singh A, Rosenthal PJ. Characterization of native and recombinant falcipain-2, a principal trophozoite cysteine protease and essential hemoglobinase of Plasmodium falciparum. J Biol Chem 2000; 275: 29000-10.

68 Berman PA, Adams PA. Artemisinin enhances heme-catalysed oxidation of lipid membranes. Free Radic Biol Med 1997; 22: 1283-8.

69 Krishna S, Uhlemann AC, Haynes RK. Artemisinins: mechanisms of action and potential for resistance. Drug Resist Updat 2004; 7: 233 - 44.

70 Posner $\mathrm{GH}$, Oh $\mathrm{CH}$. A simple chemical model system to probe the mechanism(s) for the antimalarial activity of artemisinin(qinghaosu). J Am Chem Soc 1992; 114: 8328 -9.

71 Meshnick SR, Yang YZ, Lima V, Kuypers F, Kamchonwongpaisan S, Yuthavong Y. Iron-dependent free radical generation from the antimalarial agent artemisinin (qinghaosu). Antimicrob Agents Chemother 1993; 37: 1108-14.

72 Butler AR, Gilbert BC, Hulme P, Irvine LR, Renton L, Whitwood AC. EPR evidence for the involvement of free radicals in the iron-catalysed decomposition of qinghaosu (artemisinin) and some derivatives; antimalarial action of some polycyclic endoperoxides. Free Radic Res 1998; 28: 471-6.

73 Asawamahasakda W, Ittarat I, Pu YM, Ziffer H, Meshnick SR. Reaction of antimalarial endoperoxides with specific parasite proteins. Antimicrob Agents Chemother 1994; 38: 1854-8.

74 Bhisutthibhan J, Meshnick SR. Immunoprecipitation of [(3)H]dihydroartemisinin translationally controlled tumor protein (TCTP) adducts from Plasmodium falciparum-infected erythrocytes by using anti-TCTP antibodies. Antimicrob Agents Chemother 2001; 45: 2397-9. 
75 Eckstein-Ludwig U, Webb RJ, Van Goethem ID, East JM, Lee AG, Kimura $\mathrm{M}$ et al. Artemisinins target the SERCA of Plasmodium falciparum. Nature 2003; 424: 957-61.

76 Uhlemann AC, Cameron A, Eckstein-Ludwig U, Fischbarg J, Iserovich P, Zuniga FA et al. A single amino acid residue can determine the sensitivity of SERCAs to artemisinins. Nat Struct Mol Biol 2005; 12: 628-9.

77 Parapini S, Basilico N, Mondani M, Olliaro P, Taramelli D, Monti D. Evidence that haem iron in the malaria parasite is not needed for the antimalarial effects of artemisinin. FEBS Lett 2004; 575: $91-4$.

78 Efferth T, Oesch F. Oxidative stress response of tumor cells: microarray-based comparison between artemisinins and anthracyclines. Biochem Pharmacol 2004; 68: 3-10.

79 Efferth T, Briehl MM, Tome ME. Role of antioxidant genes for the activity of artesunate against tumor cells. Int J Oncol 2003; 23: 1231 -5.

80 Efferth T, Volm M. Glutathione-related enzymes contribute to resistance of tumor cells and low toxicity in normal organs to artesunate. In Vivo 2005; 19: 225 - 32.

81 Shterman N, Kupfer B, Moroz C. Comparison of transferrin receptors, iron content and isoferritin profile in normal and malignant human breast cell lines. Pathobiology 1991; 59: 19-25.

82 Sutherland R, Delia D, Schneider C, Newman R, Kemshead J, Greaves M. Ubiquitous cell-surface glycoprotein on tumor cells is proliferation-associated receptor for transferrin. Proc Natl Acad Sci U S A 1981; 78: 4515-9.

83 Gatter KC, Brown G, Trowbridge IS, Woolston RE, Mason DY. Transferrin receptors in human tissues: their distribution and possible clinical relevance. J Clin Pathol 1983; 36: 539-45.

84 Efferth T, Benakis A, Romero MR, Tomicic M, Rauh R, Steinbach D et al. Enhancement of cytotoxicity of artemisinins toward cancer cells by ferrous iron. Free Radic Biol Med 2004; 37: 998 - 1009.

85 Moore JC, Lai H, Li JR, Ren RL, McDougall JA, Singh NP et al. Oral administration of dihydroartemisinin and ferrous sulfate retarded implanted fibrosarcoma growth in the rat. Cancer Lett 1995; 98: 83-7.

86 Singh NP, Lai H. Selective toxicity of dihydroartemisinin and holotransferrin towards human breast cancer cells. Life Sci 2001; 70: 49-56.

87 Lai H, Sasaki T, Singh NP, Messay A. Effects of artemisinin-tagged holotransferrin on cancer cells. Life Sci 2005; 76: 1267-79.

88 Meshnick SR, Yang YZ, Little B. Alkylation of proteins by artemisinin. Effect of heme, $\mathrm{pH}$ and drug structure. Biochem Pharmacol 1994; 48: 569-73.

89 Gachet Y, Tournier S, Lee M, Lazaris-Karatzas A, Poulton T, Bommer UA. The growth-related, translationally controlled protein P23 has properties of a tubulin binding protein and associates transiently with microtubules during the cell cycle. J Cell Sci 1999; 112: 1257 71.

90 Baudet C, Perret E, Delpech B, Kaghad M, Brachet P, Wion D et al. Differentially expressed genes in C6.9 glioma cells during vitamin D-induced cell death program. Cell Death Differ 1998; 5: 116-25.

91 Bommer UA, Thiele BJ. The translationally controlled tumour protein (TCTP). Int J Biochem Cell Biol 2004; 36: 379-85.

92 Folkman J. The role of angiogenesis in tumor growth. Semin Cancer Biol 1992; 3: 65-71.

93 Kerbel R, Folkman J. Clinical translation of angiogenesis inhibitors. Nat Rev Cancer 2002; 2: 727-39.

94 Shimizu K, Oku N. Cancer anti-angiogenic therapy. Biol Pharm Bull 2004; 27: 599-605.

95 Chen HH, Zhou HJ, Fang X. Inhibition of human cancer cell line growth and human umbilical vein endothelial cell angiogenesis by artemisinin derivatives in vitro. Pharmacol Res 2003; 48: 231 -6.

96 Chen HH, Zhou HJ, Wang WQ Wu GD. Antimalarial dihydroartemisinin also inhibits angiogenesis. Cancer Chemother Pharmacol 2004; 53: $423-32$.

97 Chen HH, Zhou HJ, Wu GD, Lou XE. Inhibitory effects of artesunate on angiogenesis and on expressions of vascular endothelial growth factor and VEGF receptor KDR/flk-1. Pharmacology 2004; 71: 1 - 9.

98 Dell'Eva R, Pfeffer U, Vene R, Anfosso L, Forlani A, Albini A et al. Inhibition of angiogenesis in vivo and growth of Kaposi's sarcoma xenograft tumors by the anti-malarial artesunate. Biochem Pharmacol 2004; 68: 2359-66

99 Huan-huan C, Li-Li Y, Shang-Bin L. Artesunate reduces chicken chorioallantoic membrane neovascularisation and exhibits antiangiogenic and apoptotic activity on human microvascular dermal endothelial cell. Cancer Lett 2004; 211: $163-73$.
100 Anfosso L, Efferth T, Albini A, Pfeffer U. Microarray expression profiles of angiogenesis-related genes predict tumor cell response to artemisinins. Pharmacogenomics J 2006; 6: 269- 78.

${ }^{101}$ Li Y, Shan F, Wu JM, Wu GS, Ding J, Xiao D et al. Novel antitumor artemisinin derivatives targeting G1 phase of the cell cycle. Bioorg Med Chem Lett 2001; 11: 5-8.

102 Sadava D, Phillips T, Lin C, Kane SE. Transferrin overcomes drug resistance to artemisinin in human small-cell lung carcinoma cells. Cancer Lett 2002; 179: $151-6$.

${ }^{103}$ Wang Q, Wu LM, Zhao Y, Zhang XL, Wang NP. The anticancer effect of artesunate. and its mechanism. Yao Xue Xue Bao 2002; 37: 477-8.

104 Singh NP, Lai HC. Artemisinin induces apoptosis in human cancer cells. Anticancer Res 2004; 24: 2277-80.

105 Yamachika E, Habte T, Oda D. Artemisinin: an alternative treatment for oral squamous cell carcinoma. Anticancer Res 2004; 24: 2153 - 60.

106 Baselga J. Why the epidermal growth factor receptor. The rationale for cancer therapy.. Oncologist 2002; 7: 2-8.

${ }^{107}$ Efferth T, Ramirez T, Gebhart E, Halatsch ME. Combination treatment of glioblastoma multiforme cell lines with the anti-malarial artesunate and the epidermal growth factor receptor tyrosine kinase inhibitor OSI-774. Biochem Pharmacol 2004; 67: 1689-700.

108 Chen HH, Zhou HJ, Wang WQ Wu GD. Antimalarial dihydroartemisinin also inhibits angiogenesis. Cancer Chemother Pharmacol 2004; 53: $423-32$.

109 Disbrow GL, Baege AC, Kierpiec KA, Yuan H, Centeno JA, Thibodeaux CA et al. Dihydroartemisinin is cytotoxic to papillomavirus-expressing epithelial cells in vitro and in vivo. Cancer Res 2005; 65: $10854-61$.

${ }^{110}$ Lai H, Singh NP. Oral artemisinin prevents and delays the development of 7,12-dimethylbenz[a]anthracene (DMBA)-induced breast cancer in the rat. Cancer Lett 2006; 231: $43-8$.

111 Berger TG, Dieckmann D, Efferth T, Schultz ES, Funk JO, Baur A et al. Artesunate in the treatment of metastatic uveal melanoma-first experiences. Oncol Rep 2005; 14: 1599-603.

112 Singh NP, Panwar VK. Case report of a pituitary macxroadenoma treated with artemether. Integr Cancer Ther 2006; 5: 391 -4.

113 Haynes RK. Artemisinin and derivatives: the future for malaria treatment. Curr Opin Infect Dis 2001; 14: 719-26.

114 Woodrow CJ, Haynes RK, Krishna S. Artemisinins. Postgrad Med J 2005; 81: $71-8$.

115 Yang YZ, Little B, Meshnick SR. Alkylation of proteins by artemisinin. Effects of heme, pH, and drug structure. Biochem Pharmacol 1994; 48: $569-73$.

116 Payne AG. Exploiting intracellular iron and iron-rich compounds to effect tumor cell lysis. Med Hypotheses 2003; 61: 206 - 9.

117 Lyss G, Knorre A, Schmidt TJ, Pahl HL, Merfort I. The anti-inflammatory sesquiterpene lactone helenalin inhibits the transcription factor NF-kappaB by directly targeting p65. J Biol Chem 1998; 273: 33508 16.

118 Castro V, Murillo R, Klaas CA, Meunier C, Mora G, Pahl HL et al. Inhibition of the transcription factor NF-kappa B by sesquiterpene lactones from Podachaenium eminens. Planta Med 2000; 66: 591 - 5 .

119 Müller S, Murillo R, Castro V, Brecht V, Merfort I. Sesquiterpene lactones from Montanoa hibiscifolia that inhibit the transcription factor NF-kappa B. J Nat Prod 2004; 67: 622 - 30.

${ }^{120}$ Rungeler P, Castro V, Mora G, Goren N, Vichnewski W, Pahl HL, Merfort I et al. Inhibition of transcription factor NF-kappaB by sesquiterpene lactones: a proposed molecular mechanism of action. Bioorg Med Chem 1999; 7: 2343-52.

${ }^{121}$ Garcia-Pineres AJ, Castro V, Mora G, Schmidt TJ, Strunck E, Pahl HL et al. Cysteine 38 in p65/NF-kappaB plays a crucial role in DNA binding inhibition by sesquiterpene lactones. J Biol Chem 2001; 276: 39713 20.

122 Siedle B, Garcia-Pineres AJ, Murillo R, Schulte-Monting J, Castro V, Rungeler $\mathrm{P}$ et al. Quantitative structure-activity relationship of sesquiterpene lactones as inhibitors of the transcription factor NF-kappaB. J Med Chem 2004; 47: 6042 - 54.

123 Wagner S, Hofmann A, Siedle B, Terfloth L, Merfort I, Gasteiger J. Development of a structural model for NF-kappaB inhibition of sesquiterpene lactones using self-organizing neural networks. J Med Chem 2006; 49: 2241 - 52 .

${ }^{124}$ Aldieri E, Atragene D, Bergandi L, Riganti C, Costamagna C, Bosia A et al. Artemisinin inhibits inducible nitric oxide synthase and nuclear factor NF-kB activation. FEBS Lett 2003; 552: 141 - 4. 
125 Li WD, Dong YJ, Tu YY, Lin ZB. Dihydroarteannuin ameliorates lupus symptom of BXSB mice by inhibiting production of TNF-alpha and blocking the signaling pathway NF-kappaB translocation. Int Immunopharmacol 2006; 6: 1243 - 50.

126 Tripathi AK, Sullivan DJ, Stins MF. Plasmodium falciparum-infected erythrocytes increase intercellular adhesion molecule 1 expression on brain endothelium through NF-kappaB. Infect Immunol 2006; 74: 3262-70.

127 Geldre E van, Vergauwe A, Eeckhout E van den. State of the art of the production of the antimalarial compound artemisinin in plants. Plant Mol Biol 1997; 33: 199-209. Erratum in: Plant Mol Biol 1998;38: 1271 .

128 Abdin MZ, Israr M, Rehman RU, Jain SK. Artemisinin, a novel antimalarial drug: biochemical and molecular approaches for enhanced production. Planta Med 2003; 69: 289-99.

129 Schmid G, Hofheinz W. Total synthesis of qinghaosu. J Am Chem Soc 1983; 105: 624-5.

130 Ravindranathan T, Anil Kumar M, Menon RB, Hiremath SV. Stereoselective synthesis of artemisinin. Tetrahedron Lett 1990; 31: 755 -8.

131 Avery MA, Chong WKM, Jennings-White C. Stereoselective total synthesis of (dextro)-artemisinin, the antimalarial constituent of Artemisia annua L. J Am Chem Soc 1992; 114: 974 - 9.

132 Jefford CW. Synthetic peroxides as antimalarials. Curr Opin Investig Drugs 2004; 5: 866- 72 .

133 Laughlin JC. Agricultural production of artemisinin - a review. Trans R Soc Trop Med Hyg 1994; 88: S21 - 2 .

134 Delabays N, Simmonnet X, Gaudin M. The genetics of artemisinin content in Artemisia annua L. and the breeding of high yielding cultivars. Curr Med Chem 2001; 8: 1795-801.
135 Jansen FH. The herbal tea approach for artemisinin as a therapy for malaria? Trans R Soc Trop Med Hyg 2006; 100: 285 - 6.

136 De Jesus-Gonzalez L, Weathers PJ. Tetraploid Artemisia annua hairy roots produce more artemisinin than diploids. Plant Cell Rep 2003; 21: $809-13$.

137 Souret FF, Kim Y, Wyslouzil BE, Wobbe KK, Weathers PJ. Scale-up of Artemisia annua L. hairy root cultures produces complex patterns of terpenoid gene expression. Biotechnol Bioeng 2003; 83: 653-67.

138 Nair MS, Acton N, Klayman DL, Kendrick K, Basile DV, Mante S. Production of artemisinin in tissue cultures of Artemisia annua. J Nat Prod 1986; 49: $504-7$.

139 Elmarakby SA, el-Feraly FS, Elsohly HN, Croom EM, Hufford CD. Microbial transformation studies on arteannuin B. J Nat Prod 1987; 50: $903-9$.

140 Martin VJ, Pitera DJ, Withers ST, Newman JD, Keasling JD. Engineering a mevalonate pathway in Escherichia coli for production of terpenoids. Nat Biotechnol 2003; 21: 796 -802.

141 Hampton T. Collaboration hopes microbe factories can supply key antimalaria drug. JAMA 2005; 293: 785 - 7.

142 Ro DK, Paradise EM, Ouellet M, Fisher KJ, Newman KL, Ndungu JM et al. Production of the antimalarial drug precursor artemisinic acid in engineered yeast. Nature 2006; 440: 940-3.

143 Bertea CM, Freije JR, van der Woude H, Verstappen FW, Perk L, Marquez $\mathrm{V}$ et al. Identification of intermediates and enzymes involved in the early steps of artemisinin biosynthesis in Artemisia annua. Planta Med 2005; 71: 40-7.

${ }^{144}$ Liu C, Zhao Y, Wang Y. Artemisinin: current state and perspective for biotechnological production of an antimalarial drug. Appl Microbiol Biotechnol 2006; 72: $11-20$. 